\title{
Commentary \\ How to prevent leaky vessels during reperfusion? Just keep that glycocalyx sealant in place!
}

Jurgen WGE VanTeeffelen

Department of Physiology, Cardiovascular Research Institute Maastricht, Maastricht University, UNS 50, 6229 ER Maastricht, PO Box 616 , 6200 MD Maastricht, the Netherlands

Corresponding author: Jurgen WGE VanTeeffelen, J.vanTeeffelen@FYS.unimaas.nl

Published: 15 July 2008

Critical Care 2008, 12:167 (doi:10.1186/cc6939)

This article is online at http://ccforum.com/content/12/4/167

(C) 2008 BioMed Central Ltd

See related research by Bruegger et al., http://ccforum.com/content/12/3/R73

\begin{abstract}
Myocardial edema is a hallmark of ischemia-reperfusion-related cardiac injury. Ischemia-reperfusion has been shown to result in degradation of the endothelial glycocalyx. The glycocalyx is the gellike mesh of polysaccharide structures and absorped plasma proteins on the luminal side of the vasculature, and in the past decade has been shown to play an important role in protection of the vessel wall, including its barrier properties. Prevention of glycocalyx loss or restoration of a damaged glycocalyx may be a promising therapeutic target during clinical procedures involving ischemia-reperfusion.
\end{abstract}

Prevention of coronary fluid leakage to reduce myocardial damage during ischemia-reperfusion-related clinical procedures constitutes an important therapeutic challenge. In the previous issue of Critical Care, Bruegger and colleagues presented data indicating that anticipation of glycocalyx loss may alleviate fluid leakage and edema formation in hearts undergoing occlusion and subsequent reperfusion [1].

\section{The glycocalyx: protector of endothelial function}

The glycocalyx is a negatively charged, gel-like mesh of polysaccharide structures and absorped plasma proteins on the luminal side of all blood vessels, and in the past decade has been shown to play an important role in protection of the vessel wall [2]. Major insight into the functional properties of the glycocalyx has been provided in past decades by intravital microscopic studies of striated muscle microcirculation in rodents. These studies showed that the glycocalyx constitutes a voluminous intravascular barrier for flowing blood and macromolecules [3], and that enzymatic glycocalyx degradation is associated with an increased adhesiveness of the endothelium for platelets and leucocytes [4] and with an impaired nitric oxide (NO)-mediated shear-dependent vaso- dilation of arterioles [5]. In addition, glycocalyx treatment in isolated hearts was demonstrated to result in an increased fluid leakage $[6,7]$, underlying the contribution of the glycocalyx to the vascular permeability barrier in conjunction with the endothelial cells (double barrier concept $[1,7]$ ).

More specific experimental data have been provided indicating that it is the colloid osmotic pressure difference across the glycocalyx rather than the pressure difference between the interstitial space and plasma that opposes fluid filtration in the Starling balance [8]. Protection of the glycocalyx may therefore be an essential facet when considering treatment of excessive fluid loss in clinical practice.

\section{Glycocalyx degradation during ischemia-reperfusion}

Using a highly standardized protocol of ischemia-reperfusion, Bruegger and colleagues studied the effect of exogenous NO administration on fluid leakage and glycocalyx damage in Krebs-Henseleit-buffered isolated guinea pig hearts, a model this group has been using for many years $[1,7,9]$. In the model, dynamic changes in fluid filtration are measured by repeated collection of the transudate appearing at the epicardial surface and dripping off the apex of the heart.

Bruegger and colleagues demonstrated that the increase in fluid filtration and subsequent edema formation after ischemia-reperfusion was completely abolished in the hearts when exogenous NO was administered to the perfusate [1]. The reduction in fluid leakage was accompanied by a $20 \%$ to $40 \%$ reduction in cumulative heparan sulfate release in the coronary venous effluent, suggesting that NO partially prevented shedding of these glycosaminoglycans from the

$\mathrm{NO}=$ nitric oxide 
glycocalyx. This prevention was also evidenced by a modest preservation of glycocalyx structures on the vascular endothelium in the microscopic images obtained after the experiment.

The authors hypothesize that the action of NO on glycocalyx protection against shedding was due to scavenging of oxygen-derived free radicals liberated upon reoxygenation [1]. Indeed, increased oxidative stress has been demonstrated to be the common denominator underlying glycocalyx loss during atherogenic, inflammatory, and hyperglycemic conditions [1014]. With respect to the source of free radicals involved in glycocalyx degradation during ischemia-reperfusion, RubioGayosso and colleagues provided evidence that, at least in the cremaster muscle, the oxygen radical-producing enzyme xanthine oxidoreductase was involved [13]. This enzyme has a heparin-binding domain and therefore is probably associated with heparan sulfate glycosaminoglycans within the glycocalyx, which would explain the increased shedding of heparan sulfates during ischemia-reperfusion.

\section{Glycocalyx protection: therapeutic opportunities}

Given the pivotal role of the glycocalyx in vascular wall homeostasis, restoration of a damaged glycocalyx may be a promising therapeutic target both in an acute critical care setting as well as in the treatment of chronic vascular disease. Free radical scavengers or pharmacological blockers of radical production are useful to diminish the oxygen radical stress on the glycocalyx [11], while drugs that can increase glycocalyx production or prevent proteolytic activity may prevent or restore induced glycocalyx loss [9,12]. Finally, infusion of glycocalyx components to reconstitute lost glycocalyx might be useful during clinical interventions.

Infusion of hyaluronic acid glycosaminoglycans before or shortly after the initiation of cremaster tissue reperfusion almost fully restored the impaired barrier properties of the glycocalyx in the study of Rubio-Gassayo and colleagues [13]. In another cremaster study, addition of heparan sulfates and heparin was demonstrated to alleviate venular leucocyte adhesion associated with glycocalyx damage; intravital microscopy illustrated that the infused components actually attached to the venular luminal surface [4]. Heparin administration also reduced the detrimental effect of ischemiareperfusion injury on glycocalyx integrity in the study of RubioGassayo and colleagues [13]; although this was suggested to be due to a heparin-induced displacement of xanthine oxidoreductase from the glycocalyx, it is probable that the beneficial effect of heparin actually reflected some reconstitution of the glycocalyx.

Worthy of note is the observation that administration of heparin in control, nonchallenged, mice was associated with an impaired shear-dependent NO-mediated arteriolar dilation and loss of glycocalyx barrier properties [5]. This observation suggests that heparin can have an adverse effect on the integrity of the glycocalyx in the healthy situation - potentially by the displacement of heparan sulfate-bound proteins. The paper by Bruegger and colleagues in the previous issue of Critical Care clearly warrants further clinical attention for glycocalyx protection as a therapeutic target.

\section{Competing interests}

The author declares that they have no competing interests.

\section{Acknowledgements}

The author is supported by research grants from the Netherlands Heart Foundation (2005T073 and 2003B181) and from the Dutch Diabetes Research Foundation (2006.00.027).

\section{References}

1. Bruegger D, Rehm M, Jacob M, Chappell D, Stoeckelhuber M, Welsch U, Conzen P, Becker BF: Exogenous nitric oxide requires an endothelial glycocalyx to prevent postischemic coronary vascular leak in guinea pig hearts. Crit Care 2008, 12:R73.

2. Van Teeffelen JW, Brands J, Stroes ES, Vink H: Endothelial glycocalyx: sweet shield of blood vessels. Trends Cardiovasc Med 2007, 17:101-105.

3. Vink H, Duling BR: Identification of distinct luminal domains for macromolecules, erythrocytes, and leukocytes within mammalian capillaries. Circ Res 1996, 79:581-589.

4. Constantinescu AA, Vink H, Spaan JA: Endothelial cell glycocalyx modulates immobilization of leukocytes at the endothelial surface. Arterioscler Thromb Vasc Biol 2003, 23:1541-1547.

5. VanTeeffelen JW, Brands J, Jansen C, Spaan JA, Vink H: Heparin impairs glycocalyx barrier properties and attenuates shear dependent vasodilation in mice. Hypertension 2007, 50:261267.

6. van den Berg BM, Vink H, Spaan JA: The endothelial glycocalyx protects against myocardial edema. Circ Res 2003, 92:592594.

7. Rehm M, Zahler S, Lotsch M, Welsch U, Conzen P, Jacob M, Becker BF: Endothelial glycocalyx as an additional barrier determining extravasation of $6 \%$ hydroxyethyl starch or $5 \%$ albumin solutions in the coronary vascular bed. Anesthesio/ogy 2004, 100:1211-1223.

8. Hu X, Adamson RH, Liu B, Curry FE, Weinbaum S: Starling forces that oppose filtration after tissue oncotic pressure is increased. Am J Physiol 2000, 279:H1724-H1736.

9. Chappell D, Jacob M, Hofmann-Kiefer K, Bruegger D, Rehm M, Conzen P, Welsch U, Becker BF: Hydrocortisone preserves the vascular barrier by protecting the endothelial glycocalyx. Anesthesiology 2007, 107:776-784.

10. Mulivor AW, Lipowsky $\mathrm{HH}$ : Inflammation- and ischemiainduced shedding of venular glycocalyx. Am J Physiol 2004, 286: $\mathrm{H} 1672-\mathrm{H} 1680$.

11. Nieuwdorp $M$, van Haeften TW, Gouverneur MC, Mooij HL, van Lieshout MH, Levi M, Meijers JC, Holleman F, Hoekstra JB, Vink H, Kastelein JJ, Stroes ES: Loss of endothelial glycocalyx during acute hyperglycemia coincides with endothelial dysfunction and coagulation activation in vivo. Diabetes 2006, 55:480-486.

12. Nieuwdorp M, Meuwese MC, Mooij HL, van Lieshout MH, Hayden A, Levi M, Meijers JC, Ince C, Kastelein JJ, Vink H, Stroes ES: Tumor necrosis factor-alpha inhibition protects against endotoxin-induced endothelial glycocalyx perturbation. Atherosclerosis 2008, 12. Epub ahead of print. [doi: 10.1016/ j.atherosclerosis.2008.03.024].

13. Rubio-Gayosso I, Platts SH, Duling BR: Reactive oxygen species mediate modification of glycocalyx during ischemiareperfusion injury. Am J Physiol 2006, 290:H2247-H2256.

14. Vink $H$, Constantinescu $A A$, Spaan JA: Oxidized lipoproteins degrade the endothelial surface layer: implications for platelet-endothelial cell adhesion. Circulation 2000, 101: 1500-1502. 